\title{
Casca de mamona associada a quatro fontes de matéria orgânica para a produção de mudas de pinhão-manso
}

\author{
Rosiane de Lourdes Silva de Lima', Liv Soares Severino², Gilvan Barbosa Ferreira ${ }^{3}$, \\ Valdinei Sofiatti ${ }^{3}$, Lígia Rodrigues Sampaio ${ }^{4}$, Napoleão Esberard de Macêdo Beltrão ${ }^{4}$
}

\section{RESUMO}

Para a produção de mudas de pinhão-manso (Jatropha curcas L.) geralmente tem sido recomendado o uso de misturas de materiais orgânicos. Uma das alternativas para compor substratos e produzir mudas é a casca de mamona, que é um resíduo gerado em grande quantidade no processo de descascamento das sementes e que apresenta teores elevados de macronutrientes. Para testar o efeito do uso da casca de mamona como substrato, conduziu-se experimento em casa de vegetação, na Embrapa Algodão, no período de outubro a dezembro de 2006. Adotou-se delineamento inteiramente casualizado, com quatro repetições e duas plantas por parcela. Os tratamentos constituíram-se de misturas de terra e casca de mamona com um dos seguintes materiais: composto de lixo, esterco bovino, lodo de esgoto e torta de mamona. O tratamento-controle foi composto por terra e casca de mamona. Aos 55 dias após o semeio, mediram-se a altura da planta, o número de folhas, a área foliar, o diâmetro caulinar, a massa seca da parte aérea e das raízes e os teores foliares de $\mathrm{N}, \mathrm{P}, \mathrm{K}, \mathrm{Ca}, \mathrm{Mg}$, e $\mathrm{S}$. O uso de apenas terra com casca de mamona moída proporciona menor crescimento das mudas. A adição do composto de lixo urbano, lodo de esgoto ou torta de mamona à composição do substrato proporciona melhor desenvolvimento das mudas. Mudas de pinhão manso cultivadas em substratos compostos por misturas de terra, casca de mamona e esterco bovino apresentaram os maiores teores foliares de fósforo, magnésio e enxofre, enquanto aquelas cultivadas em substrato composto por misturas de terra, casca de mamona e lodo de esgoto apresentaram os maiores teores foliares de potássio e cálcio.

Palavras-chave: Jatropha curcas, substratos, propagação.

\section{ABSTRACT}

\section{Castor hull combined with four organic matter sources for physic nut seedling production}

Substrates consisting of mixtures of soil and organic materials have usually been recommended for production of physic nut (Jatropha curcas L.) seedlings. Castor hull is a residue produced in large quantities during the hulling process. This residue contains high amounts of macronutrients. The objective of this study was to evaluate four organic materials for mixing with soil and castor hull. The experiment was conducted in a greenhouse at EMBRAPA Cotton Research Center between October and December 2006. The treatments were arranged in a complete randomized design with four replications and two plants per plot. Treatments were a mixture of soil and castor hull with one of the following materials: garbage compost, bovine manure, sewage sludge and castor presscake. The Control was a mixture of soil and castor hull. At 55 days after sowing, data on plant height, number of leaves, leaf area, stem diameter, dry weight of shoots and roots and leaf content of N, P, K, Ca, Mg and S were measured. All substrates were found suitable for production of physic nut seedlings, however the use of soil with castor hull only showed the lowest seedling

Recebido para publicação em março de 2010 e aprovado em dezembro de 2010

'Engenheira Agrônoma, Doutora, Departamento de Produção Vegetal, FAPESP/CNPq/PB. Rua Oswaldo Cruz, 1143, Centenário, Caixa Postal 174, 58107-720 Campina Grande -PB. Brasil. limarosiane@yahoo.com.br

${ }^{2}$ Engenheiro Agrônomo, Mestre, Embrapa Algodão. Rua Oswaldo Cruz, 1143, Centenário, Caixa Postal 174, 58107-720 Campina Grande - PB. Brasil. liv@cnpa.embrapa.br

${ }^{3}$ Engenheiro Agrônomo, Doutor, Embrapa Algodão. Rua Oswaldo Cruz, 1143, Centenário, Caixa Postal 174, 58107-720 Campina Grande - PB. Brasil. gilvan.ferreira@cnpa.embrapa.br; vsofiatti@cnpa.embrapa.br; napoleão@cnpa.embrapa.br

${ }^{4}$ Química Industrial, Mestre, Departamento de Química Industrial, Universidade Federal de Campina Grande, Campina Grande, Rua Oswaldo Cruz 1143, Centenário, Caixa Postal 174, 58.107-720 Campina Grande - PB. Brasil. liggiasampaio@yahoo.com.br 
growth. The ratios $1: 1$ and 1:2 (v/v) of soil with organic material (post-mineralization) usually produce macronutrientrich substrates. Addition of domestic waste, sewage sludge or castor presscake composts to the substrate promotes higher growth and plant nutrition. Macronutrient leaf contents did not reflect the corresponding nutrient content measured in the organic material used in the substrate composition

Key words: Jatropha curcas L., substrates, propagation

\section{INTRODUÇÃO}

O pinhão-manso pode ser propagado por sementes ou por estacas (Lima et al., 2010). As mudas de estacas têm a vantagem de ser mais precoces, mas, por outro lado, geram plantas com sistema radicular deficiente, sem a raiz pivotante (Noor Camellia et al., 2009), limitando-se apenas às raízes secundárias e superficiais, o que deixa a planta sujeita ao tombamento e mais sensível à falta de água e nutrientes no solo (Shivastava \& Banerijee, 2009). Por outro lado, as mudas obtidas de sementes, apesar de serem mais desuniformes e menos precoces, geram plantas com sistema radicular mais vigoroso (Paulino et al., 2011), permitindo maior tolerância à seca e melhor aproveitamento dos nutrientes (Heller, 1996; Arruda et al., 2004; Luíz, 2009).

Para a produção de mudas de pinhão-manso existem poucas informações sobre formulação de substratos recomendados sendo frequentemente usado pelos pequenos produtores misturas de materiais orgânicos e terra em diversas proporções. Lima et al. (2009) recomendam o uso de mistura de terra e composto de lixo urbano em proporções iguais, enquanto Paulino et al. (2011) indicam utilizar substratos à base de casca de pínus para produzir mudas de pinhão-manso em tubetes. Atualmente, com o Programa Nacional do Biodiesel, um dos produtos gerados em grande quantidade no processo de descascamento e beneficiamento das sementes de mamona e que apresenta quantidades significativas de alguns nutrientes é a casca de mamona (Severino et al., 2006). Sua utilização, para compor substratos e produzir mudas, ainda é pouco conhecida. De acordo com Lima et al. (2006), para a obtenção de um bom substrato é aconselhável o uso de misturas de dois ou mais materiais que possibilitem boa aeração, drenagem e adequada disponibilidade de nutrientes para as plantas. Por outro lado, é importante que na escolha dos materiais para compor substratos sejam levados em consideração sua disponibilidade na região e o custo de obtenção (Lima et al., 2009).

Materiais com boa aeração, como casca de arroz carbonizada, casca de pínus, mucilagem de sisal, casca de café ou de amendoim (Lima et. al. 2006) e a própria casca do fruto do pinhão-manso, podem ser utilizados na formulação do substrato quando combinado com outros materiais ricos em nutrientes, a exemplo da torta de mamona, cama de frango, do lodo de esgoto, composto de lixo urbano, húmus de minhoca, da bagana de carnaubeira, dentre outros (Severino et al., 2006).

Objetivou-se com este trabalho avaliar o crescimento e os teores foliares de N, P, K, Ca, Mg e S em mudas de pinhão-manso cultivadas em substratos compostos por misturas de terra e casca de mamona associada a composto de lixo, esterco bovino, lodo de esgoto e torta de mamona.

\section{MATERIAL E MÉTODOS}

O pinhão-manso é uma cultura sem variedade ou cultivar definido, existindo apenas acessos originados de diversas partes do mundo que apresentam grande variabilidade genética, provocando a geração de indivíduos com hábito de crescimento diferenciado, produtividade desuniforme e produção de frutos com teor de óleo heterogêneo. Essa grande variabilidade resulta em material propagativo com elevado grau de desuniformidade, apresentando indivíduos na mesma população com características fenotípicas bem diferenciadas e potencial produtivo que pode comprometer o investimento agrícola. Assim, por não dispor de sementes de uma variedade, cultivar ou acesso recomendado, o material propagativo foi originado de sementes procedentes de diversos acessos de pinhão-manso coletados no Estado de Pernambuco.

Sementes de pinhão-manso foram cultivadas em vasos com capacidade para $3 \mathrm{dm}^{3}$, em casa de vegetação, no período de outubro a dezembro de 2006. Adotou-se delineamento inteiramente casualizado com cinco tratamentos, quatro repetições e duas plantas por parcela. Os tratamentos consistiram de misturas de casca de mamona triturada, terra e mais uma das seguintes fontes de matéria orgânica: esterco bovino, composto de lixo, lodo de esgoto e torta de mamona, em proporções volumétricas iguais. O tratamento-testemunha foi padronizado por uma mistura de terra e casca de mamona triturada na proporção de 1:1 (v/v).

Utilizou-se para compor os substratos terra de subsolo, cujas características químicas encontram-se na Tabela 1.

Foram determinados os teores de nutrientes na casca de mamona, no composto de lixo, no esterco bovino, no lodo de esgoto e na torta de mamona (Tabela 2) antes da 
formulação das misturas. Após a obtenção dos substratos, os elementos foram analisados quimicamente, conforme a Tabela 3 .

A casca de mamona, a terra e os demais materiais orgânicos foram cuidadosamente homogeneizados em sacos plásticos, acondicionados nos recipientes e umedecidos até atingir a capacidade de campo. Para o acondicionamento dos substratos e cultivo das mudas utilizaram-se como recipientes vasos de polietileno com $3 \mathrm{dm}^{3}$.

Após a formulação, os substratos foram incubados por 35 dias, sendo irrigados e revolvidos duas vezes por semana. Após a incubação, semearam-se três sementes de pinhão-manso por vaso. O desbaste foi realizado dez dias após a emergência, deixando-se apenas uma planta por vaso. As plantas foram diariamente irrigadas. A cada 10 dias fez-se a retirada de plantas daninhas e pulverizações de abamectina na dose de 400 g.i.a. ha ${ }^{-1}$ com volume de calda de $200 \mathrm{~L} \mathrm{ha}^{-1}$ para controle dos ácaros branco (Polyphagotoarsonemuslatus latus) e vermelho (Tetranychus ludeni).

Aos 40 dias após a semeadura, foram tomadas as medidas de altura da planta, diâmetro caulinar, número de folhas, área foliar e massa seca da parte aérea e das raízes das mudas. A área foliar foi calculada pela fórmula $\mathrm{A}=$ 0,84(PL) ${ }^{0,99}$, em que: $\mathrm{A}=$ área foliar, $\mathrm{P}=$ comprimento da nervura principal da folha; e $\mathrm{L}$ = largura da folha (Severino etal., 2007).

Para obtenção da massa seca, a parte aérea e as raízes das mudas foram postas para secar em estufa de circulação de ar forçada a $65^{\circ} \mathrm{C}$ até atingir massa constante e, em seguida, foram moídas em moinho tipo Willey e posteriormente analisadas.

As análises químicas do material vegetal foram feitas no Laboratório de Solos e Plantas da Embrapa Algodão, segundo a metodologia proposta por Le Poidevin \& Robinson (1964). Para a medição dos teores de N, P e K, as amostras foram submetidas à digestão sulfúrica; o teor de $\mathrm{N}$ foi determinado pelo método de Nesller com leitura em espectrofotômetro a $410 \mathrm{~nm}$; o teor de $\mathrm{P}$ foi determinado pelo método do molibdato de amônio com leitura em espectrofotômetro a $660 \mathrm{~nm}$; e o teor de $\mathrm{K}$ foi determinado por fotometria de chama. Para a medição dos teores de Ca, $\mathrm{Mg}$ e $\mathrm{S}$, as amostras foram submetidas à digestão nítrica. Os teores de $\mathrm{Ca}$ e o $\mathrm{Mg}$ foram medidos por titulação complexiométrica com EDTA e o teor de $\mathrm{S}$ foi determinado pelo método do uso do Cloreto de Bário com leitura em espectrofotometria a $420 \mathrm{~nm}$.

Os dados obtidos foram submetidos à análise de variância (Teste F) e teste de Tukey a 5\% de probabilidade, conforme Ferreira (1996).

Tabela 1. Composição química do material de solo utilizado na formulação do substrato

\begin{tabular}{|c|c|c|c|c|c|c|c|c|c|c|c|}
\hline $\begin{array}{l}\text { pH } \\
(1: 2,5)\end{array}$ & $\mathrm{Ca}^{2+}$ & $\mathbf{M g}^{2+}$ & $\mathrm{Na}^{+}$ & $\begin{array}{r}\mathbf{K}^{+} \\
\mathbf{m I}\end{array}$ & $\begin{array}{l}\mathrm{SB} \\
\mathrm{Im}^{-3}\end{array}$ & $\mathbf{H}^{+}+\mathbf{A l}^{3+}$ & $\mathbf{A l}^{3+}$ & CTC & $\begin{array}{c}\mathrm{V} \\
(\%)\end{array}$ & $\begin{array}{c}\mathbf{P} \\
\left(\mathbf{m g ~ d m}^{-3}\right)\end{array}$ & $\begin{array}{c}\text { M.O } \\
\left(\mathrm{g} \mathrm{kg}^{-1}\right)\end{array}$ \\
\hline 5,4 & 52,7 & 16,2 & 3,2 & 1,0 & 73,1 & 8,3 & 4,5 & 81,4 & 90 & 27,1 & 1,0 \\
\hline
\end{tabular}

M.O = Matéria orgânica, $\mathrm{SB}=$ Soma de bases, $\mathrm{T}=$ Capacidade de troca catiônica, $\mathrm{V}=$ Saturação por bases.

Tabela 2. Teores de nitrogênio, fósforo, potássio, cálcio e magnésio contidos nos materiais utilizados na formulação dos substratos

\begin{tabular}{lccccc}
\hline Materiais orgânicos & \multicolumn{5}{c}{ Nutrientes (\%) } \\
\cline { 2 - 6 } & $\mathbf{N}$ & $\mathbf{P}$ & $\mathbf{K}$ & $\mathbf{C a}$ & $\mathbf{M g}$ \\
\hline Casca de mamona & 1,86 & 0,26 & 4,5 & 0,67 & 0,88 \\
Composto de lixo & 0,76 & 1,53 & 0,10 & 0,46 & 0,22 \\
Esterco bovino & 0,77 & 0,87 & 0,32 & 0,30 & 0,18 \\
Lodo de esgoto & 3,64 & 6,69 & 0,22 & 1,75 & 0,35 \\
Torta de mamona & 7,54 & 3,11 & 0,66 & 0,75 & 0,51 \\
\hline
\end{tabular}

Tabela 3. Composição química dos substratos utilizados para a formação de mudas de pinhão-manso cultivadas em vasos de $3 \mathrm{dm}{ }^{3}$

\begin{tabular}{|c|c|c|c|c|c|c|c|c|c|c|c|}
\hline \multirow[b]{2}{*}{ Substratos } & \multicolumn{11}{|c|}{ Características } \\
\hline & $\begin{array}{c}\text { pH } \\
\text { (água) }\end{array}$ & $\mathrm{Ca}^{2+}$ & $\mathbf{M g}^{2+}$ & $\begin{array}{c}\mathrm{Na}^{+} \\
\mathbf{m m o l}_{\mathrm{c}} \mathbf{d m}^{-3}\end{array}$ & $\mathbf{K}^{+}$ & $\mathbf{H}+\mathbf{A l}$ & $\mathbf{T}$ & V\% & $\mathrm{Al}^{3+} \mathrm{mmol}_{\mathrm{c}} \mathbf{d m}^{-3}$ & Pmg dm ${ }^{-3}$ & $\begin{array}{c}\text { M.O } \\
\left(\mathrm{g} \mathrm{kg}^{-1}\right)\end{array}$ \\
\hline Casca de mamona + terra & 6,55 & 18,9 & 16,02 & 6,95 & 7,7 & 5,77 & 55 & 90 & 0,62 & 201,7 & 13,8 \\
\hline $\mathrm{CM}+$ terra $+\mathrm{CL}$ & 6,9 & 30,6 & 13,6 & 6,25 & 11,6 & 5,17 & 67,2 & 92 & 0,37 & 162 & 12,0 \\
\hline $\mathrm{CM}+\mathrm{EB}+$ terra & 7,27 & 22,4 & 25,6 & 7,47 & 14,2 & 1,65 & 71 & 98 & 0,12 & 190 & 12,0 \\
\hline $\mathrm{CM}+\mathrm{LE}+$ terra & 7,40 & 22,5 & 16,5 & 7,70 & 16,8 & 0,00 & 63,5 & 100 & 0,0 & 530,4 & 15,5 \\
\hline $\mathrm{CM}+\mathrm{TM}+$ terra & 6,72 & 17,5 & 29,3 & 1,02 & 2,45 & 8,67 & 58,9 & 85 & 0,50 & 358,1 & 23,3 \\
\hline
\end{tabular}

$\mathrm{CM}=$ Casca de mamona; $\mathrm{CL}=$ Composto de lixo; $\mathrm{EB}=$ Esterco bovino; $\mathrm{LE}=$ Lodo de esgoto; e $\mathrm{TM}=$ torta de mamona.

Rev. Ceres, Viçosa, v. 58, n.2, p. 232-237, mar/abr, 2011 


\section{RESULTADOS E DISCUSSÃO}

A composição do substrato influenciou o crescimento das mudas de pinhão- manso em altura, diâmetro caulinar e matéria seca da parte aérea (Tabelas 4). Substratos compostos por apenas mistura de terra e casca de mamona triturada promoveram menor crescimento em altura das mudas do que os substratos em que se adicionaram composto de lixo, esterco bovino, lodo de esgoto ou torta de mamona. O esterco bovino, o lodo de esgoto e a torta de mamona apresentam elevados teores de nutrientes, mas não provocaram aumento na altura das plantas em relação ao composto de lixo urbano. As características ideais de um substrato dependem das exigências da espécie cultivada, por isso dificilmente se encontra um material que reúna sozinho todas as condições nutricionais e físicas para o adequado crescimento das plantas (Lima et al., 2006; Lima et al., 2009). Além disso, há diversos materiais que ocasionam problemas para as plantas como liberação de substâncias aleloquímicas e elevada relação $\mathrm{C} / \mathrm{N}$, tornando-se preferível o uso de misturas de dois ou mais materiais orgânicos para compor um bom substrato. Como a torta de mamona e o lodo de esgoto são materiais orgânicos ricos em N (7,54 e 3,64\%, respectivamente), era esperado que a adição desses materiais à composição do substrato promovesse maior crescimento das plantas; contudo, não se observou esse efeito. A altura das plantas variou entre 27,02 e 33,07 cm (Tabela 4). Uma explicação provável para esse efeito está no uso de um solo fértil como substrato (valor $\mathrm{V}>60 \%$ ), na composição química dos substratos orgânicos estudados e na elevada proporção de compostos orgânicos para o solo usado (mínima de 50\% de material orgânico aplicado e máximo de 67\% do volume do substrato), os quais promoveram melhoria na fertilidade do substrato, igualando o efeito dos diferentes materiais orgânicos aplicados na maioria das variáveis de crescimento e nutrição medidas no pinhão-manso. Além disso, é possível que o elevado tamanho das partículas da casca de mamona triturada tenha melhorado algumas características físicas do substrato, como a aeração e a drenagem. Resultados similares foram constatados por Lima et al (2006), os quais verificaram que a aplicação de 50\% de casca de amendoim associada a 50\% de material de solo propicia condições adequadas para o crescimento de mudas de mamoneira, espécie da mesma família do pinhão-manso. Segundo esses autores, a adição de casca de amendoim à formulação do substrato aumentou sensivelmente a porosidade do substrato e, consequentemente, a aeração do sistema radicular das plantas. Para mudas de pinhão-manso, Paulino et al. (2011) constataram que as propriedades físicas do substrato são essenciais para o pleno desenvolvimento das mudas, pois o cultivo de plantas em recipientes limita o desenvolvimento do sistema radicular, influenciando diretamente na absorção de água e nutrientes.

O número de folhas por planta, a área foliar e a matéria seca do sistema radicular de mudas de pinhão-manso não foram influenciados pela composição do substrato (Tabela 4). Aárea foliaré uma das características mais importantes na análise de crescimento, pois reflete os resultados da aplicação de determinado tratamento. Era esperado que fontes ricas em macronutrientes, a exemplo da torta de mamona, do composto de lixo urbano e do lodo de esgoto, propiciassem maior expansão dos tecidos foliares avaliados pelas medidas da área foliar. Porém, a alta fertilidade gerada nos diferentes substratos, muito superior à necessidade para a produção de mudas em geral, tendeu a igualar todos os tratamentos nas condições em que se fez este experimento. As mudas com maior diâmetro caulinar foram obtidas no substrato contendo mistura de terra, casca de mamona triturada e lodo de esgoto, o qual diferiu estatisticamente daqueles observados no substrato contendo mistura de terra, casca de mamona e esterco bovino (Tabela 4).

A matéria seca da parte aérea das mudas variou entre 5,30 e 9,55 g, sendo o menor valor observado no substrato composto por mistura de terra, casca de mamona e esterco bovino e o maior no substrato composto por mistura de terra, casca de mamona e torta de mamona (Tabela 4).

A torta de mamona é um produto resultante da extração do óleo de sementes da mamoneira; ela é rica em alguns nutrientes como nitrogênio, fósforo e potássio, sendo utilizada, principalmente, na forma de fertilizante orgânico. Lima et al. (2008), avaliando o uso de torta de mamona como adubo orgânico no crescimento inicial da mamoneira, constatataram que a aplicação de 2,0 t/ha propiciou condi-

Tabela 4. Altura de planta, número de folhas, diâmetro caulinar, área foliar, matéria seca da parte aérea e matéria seca do sistema radicular de mudas de pinhão manso cultivadas em substratos compostos por misturas de casca de mamona (CM), composto de lixo (CL), esterco bovino (EB), lodo de esgoto (LE), torta de mamona (TM) e terra (T)

\begin{tabular}{lcccccc}
\hline Substratos & $\begin{array}{c}\text { Altura } \\
(\mathbf{c m})\end{array}$ & $\mathbf{N}^{\circ}$ folhas & $\begin{array}{c}\text { Diâmetro } \\
\text { caulinar }(\mathbf{m m})\end{array}$ & $\begin{array}{c}\text { Área foliar } \\
\left(\mathbf{c m}^{2}\right)\end{array}$ & $\begin{array}{c}\text { MSPA } \\
(\mathbf{g})\end{array}$ & $\begin{array}{c}\text { MSRaiz } \\
(\mathbf{g})\end{array}$ \\
\hline $\mathrm{CM}+\mathrm{TERRA}$ & $27,02 \mathrm{~b}$ & $7,5 \mathrm{a}$ & $1,3 \mathrm{ab}$ & $513,57 \mathrm{a}$ & $6,74 \mathrm{ab}$ & $1,78 \mathrm{a}$ \\
$\mathrm{CM}+\mathrm{CL}+\mathrm{T}$ & $33,07 \mathrm{a}$ & $9,5 \mathrm{a}$ & $1,4 \mathrm{ab}$ & $620,96 \mathrm{a}$ & $8,29 \mathrm{a}$ & $1,78 \mathrm{a}$ \\
$\mathrm{CM}+\mathrm{EB}+\mathrm{T}$ & $31,62 \mathrm{ab}$ & $9,0 \mathrm{a}$ & $1,07 \mathrm{~b}$ & $652,56 \mathrm{a}$ & $5,30 \mathrm{~b}$ & $1,06 \mathrm{a}$ \\
$\mathrm{CM}+\mathrm{LE}+\mathrm{T}$ & $27,97 \mathrm{ab}$ & $10,0 \mathrm{a}$ & $1,47 \mathrm{a}$ & $607,43 \mathrm{a}$ & $8,09 \mathrm{ab}$ & $1,74 \mathrm{a}$ \\
$\mathrm{CM}+\mathrm{TM}+\mathrm{T}$ & $31,17 \mathrm{ab}$ & $11,75 \mathrm{a}$ & $1,35 \mathrm{ab}$ & $734,30 \mathrm{a}$ & $9,55 \mathrm{a}$ & $2,02 \mathrm{a}$ \\
\hline
\end{tabular}

* Valores seguidos da mesma letra minúscula na coluna não diferem entre si pelo teste de Tukey a $5 \%$. 
ções favoráveis para o crescimento das plantas, resultado atribuído ao alto teor de nitrogênio em sua composição. Por ser um resíduo de rápida mineralização (Severino et al., 2005), a torta de mamona é excelente fonte de matéria orgânica para a formulação de substratos e cultivo de plantas.

Os teores foliares de todos os nutrientes, exceto o $\mathrm{Ne}$ o K, foram influenciados pelos substratos (Tabela 5). Embora não se tenha constatado diferenças estatísticas para o teor foliar de $\mathrm{N}$, observou-se que o teor mais elevado deste nutriente $\left(28,7 \mathrm{~g} \mathrm{~kg}^{-1}\right)$ foi constatado no tecido foliar das plantas cultivadas em substrato contendo mistura de terra, casca de mamona e composto de lixo urbano, e o mais baixo $\left(13,13 \mathrm{~g} \mathrm{~kg}^{-1}\right)$, em plantas cultivadas no substrato contendo mistura de terra, casca de mamona e esterco bovino (Tabela 5).

O substrato contendo mistura de terra, casca de mamona e esterco bovino e aquele composto por misturas de terra, casca de mamona e torta de mamona ou contendo composto de lixo propiciaram condições favoráveis para a obtenção de plantas com elevados teores foliares de $\mathrm{P}$ e $\mathrm{S}$ em seus tecidos. Menores teores de $\mathrm{P}$ foram constatados em plantas cultivadas em substratos contendo misturas de terra e casca de mamona e mistura de terra, casca de mamona e lodo de esgoto, embora este seja excelente fonte de $\mathrm{P}$ (Colodro et al., 2007). Por outro lado, o menor teor do nutriente $\mathrm{S}$ foi constatado em mudas cultivadas em substratos contendo misturas de terra, casca de mamona e torta de mamona e mistura de terra, casca de mamona e lodo de esgoto (Tabela 5).

Os teores de potássio estiveram sempre acima dos níveis considerados altos (96 a $656 \mathrm{mg} \mathrm{dm}^{-3}$ no substrato), tendo pouca influência sobre as variáveis medidas. Apesar de sua absorção ter sido mais elevada em substratos que tiveram os maiores teores desse nutriente (CL, EB e LE), não houve diferença significativa entre mudas cultivadas nos diferentes substratos

Os teores de $\mathrm{Ca}$ e $\mathrm{Mg}$ variaram amplamente no tecido da parte aérea das mudas em razão da composição do substrato (Tabela 5). O maior teor de Ca foi constatado em plantas cultivadas em substrato contendo composto por mistura de terra, casca de mamona e lodo de esgoto, reflexo do alto teor desse elemento no lodo de esgoto (Tabela 2). O maior teor de $\mathrm{Mg}$ foi encontrado quando se cultivou o pinhão-manso em substrato contendo terra, casca e torta de mamona, e só não foi superior ao teor observado no tecido foliar de mudas cultivadas em substrato composto por mistura de terra e casca de mamona e esterco bovino. Os menores teores de $\mathrm{Ca}$ e $\mathrm{Mg}$ foram verificados nos substratos contendo apenas terra e casca de mamona e naquele composto formado por terra, casca de mamona e lodo de esgoto.

Tabela 5. Teores de N, P, K, Ca, $\mathrm{Mg}$ e S ( $\left.\mathrm{g} \mathrm{kg}^{-1}\right)$ em mudas de pinhão manso cultivadas em substratos compostos por misturas de casca de mamona (CM), composto de lixo (CL), esterco bovino (EB), lodo de esgoto (LE), torta de mamona (TM) e terra (T)

\begin{tabular}{llcclcl}
\hline \multirow{2}{*}{ Substratos } & $\mathbf{N}$ & $\mathbf{P}$ & $\mathbf{K}$ & $\mathbf{C a}$ & $\mathbf{M g}$ & $\mathbf{S}$ \\
\cline { 2 - 7 } & \multicolumn{7}{c}{$\left(\mathbf{g ~ k g}^{-1}\right)$} \\
CM + TERRA & $21,7 \mathrm{a}$ & $0,14 \mathrm{~b}$ & $16,7 \mathrm{a}$ & $5,5 \mathrm{~b}$ & $11,5 \mathrm{bc}$ & $1,1 \mathrm{~b}$ \\
CM+CL+T & $28,7 \mathrm{a}$ & $0,18 \mathrm{~b}$ & $18,5 \mathrm{a}$ & $7,2 \mathrm{ab}$ & $11,8 \mathrm{~b}$ & $1,2 \mathrm{ab}$ \\
CM+EB+T & $13,13 \mathrm{a}$ & $0,48 \mathrm{a}$ & $19,0 \mathrm{a}$ & $5,8 \mathrm{~b}$ & $18,4 \mathrm{a}$ & $1,5 \mathrm{a}$ \\
CM+LE+T & $23,7 \mathrm{a}$ & $0,14 \mathrm{~b}$ & $19,5 \mathrm{a}$ & $9,7 \mathrm{a}$ & $8,5 \mathrm{c}$ & $1,2 \mathrm{~b}$ \\
CM+TM+T & $21,5 \mathrm{a}$ & $0,44 \mathrm{a}$ & $13,2 \mathrm{a}$ & $6,2 \mathrm{~b}$ & $19,0 \mathrm{a}$ & $1,0 \mathrm{~b}$ \\
\hline
\end{tabular}

* Valores seguidos da mesma letra na coluna não diferem entre si pelo teste de Tukey a $5 \%$.

\section{CONCLUSÕES}

O uso de apenas terra com casca de mamona moída proporciona menor crescimento das mudas.

A adição do composto de lixo urbano, lodo de esgoto ou torta de mamona à composição do substrato proporciona melhor desenvolvimento das mudas.

Mudas de pinhão manso cultivadas em substratos compostos por misturas de terra, casca de mamona e esterco bovino apresentaram os maiores teores foliares de fósforo, magnésio e enxofre, enquanto aquelas cultivadas em substrato composto por misturas de terra, casca de mamona e lodo de esgoto apresentaram os maiores teores foliares de potássio e cálcio.

\section{AGRADECIMENTOS}

Ao convênio FAPESQ/PB/CNPq, pelo apoio financeiro.

\section{REFERÊNCIAS}

Arruda FP, Beltrão NEM, Andrade AP, Pereira WE \& Severino LS (2004) Cultivo de pinhão manso (Jatropha curcas L.) como alternativa para o semi-árido nordestino. Revista Brasileira de Oleaginosas e Fibrosas, 8:789-799.

Colodro G, Espíndola CR, Cassiolato AMR \& Alves MC (2007) Atividade microbiana em um latossolo degradado tratado com lodo de esgoto. Revista Brasileira de Engenharia Agrícola e Ambiental, 11:195-198.

Costa FX, Beltrão NEM, Lima VLA, Nunes Júnior ES, Guimarães MMB \& Damaceno FAV (2009) Efeito do lixo orgânico e torta de mamona nas características de crescimento de mamoneira. Engenharia Ambiental, 6:259-268.

Ferreira PV (1996) Estatística experimental aplicada à agronomia. 2.ed. Maceió: EDUFAL. 606p.

Heller J (1996) Physic nut. Jatropha curcas L. promoting the conservation and use of underutilized and neglected crops. 1. Gatersleben, Rome: Institute of Plant Genetic Resources and Crop Plant Research, 66 p. 
Le poidevin N \& Robinson LA (1964) Métodos de diagnósticos foliares utilizados nas plantações do grupo booken na Guiana inglesa: amostragem e técnica de análises. Fertilité, 21:3-11.

Lima RLS, Soares LS, Silva MIL, Jerônimo JF, Vale LS \& Beltrão NEM (2006) Substratos para produção de mudas de mamona compostos por misturas de cinco fontes de matéria orgânica. Ciência e Agrotecnologia,30:474-479.

Lima RLS, Severino LS, Albuquerque RC, Beltrão NEM \& Sampaio LR (2008) Casca e torta de mamona avaliados em vasos como fertilizantes orgânicos. Revista Caatinga, 21:102-106.

Lima RLS, Severino LS, Sampaio LR, Freire MAO, Beltrão NEM \& Arriel,NHC. Crescimento e teor foliar de nutrientes em mudas de pinhão manso (Jatropha curcas L.) em substratos contendo diferentes materiais orgânicos e fertilizante mineral. Revista Brasileira de Oleaginosas e Fibrosas, 13:29-36.

Lima RLS, Severino LS, Pereira WE, Lucena AMA, Ghreyi HR \& Arriel NHC (2009) Comprimento das estacas e parte do ramo para formação de mudas de pinhão-manso (2010). Revista Brasileira de Enhenharia agrícola e Ambiental, 14:1234-1239.

Luíz RMFCB 2009 Resposta de Jatropha curcas L. ao deficit hídrico, caractrização bioquímica e ecofisiologia.. 62p. Dissertação (Mestrado) - Universidade Técnica de Lisboa.
Noor Camellia NA, Thohirah LA, Abdullah NAP \& Mohd Khidir O (2009) Improvement on rooting quality of Jatropha curcas using indole butyrico acid (IAB). Research journal of agriculture an Biological Sciences, 5:338-343.

Paulino J, Folegatti MV, Flumignan DL, Zolin CA, Barbosa Júnior CRA \& Piedade, SMS (2011) Crescimento e qualidade de mudas de pinhão-manso produzidas em ambiente protegido. Revista Brasileira de Engenharia Agrícola e Ambiental, 15:37-46.

Severino LS, Costa FX, Beltrão NEM, Lucena AMA \& Guimarães MMB (2005) Mineralização da torta de mamona, esterco bovino e bagaço de cana estimada pela respiração microbiana. Revista de Biologia e Ciências da Terra, 5(1).

Severino LS, Lima RLS \& Beltrão NEM (2006) Composição química de onze materiais orgânicos utilizados em substratos para produção de mudas. Campina Grande, Embrapa Algodão (Comunicado Técnico no 278). 12p.

Severino LS, Vale LS \& Beltrão, NEM (2007) A simple method for measurement of Jatropha curcas leaf area. Revista Brasileira de Oleaginosas e Fibrosas, 11:9-14.

Shivastava S \& Banerijee M (2009) In vitro clonal prpagation of physic nut (Jatropha curcas L.): Influence of additives. International Jounal of integrative Biology, 3:73-79. 